The necessary and sufficient relations between the functional forms to ensure the required functionality are derived; the terms limit, differentiation, and integration are defined: and the exponential and certain trigonometric functions are discussed.

14. Assuming that $n$ values of a function $f(x)$ and its derivatives are known

$$
f^{\left(\kappa_{\iota}\right)} x_{\iota}=a_{\iota} \quad\left(\iota=1,2, \ldots, n ; \kappa_{\iota} \leqq n-1\right)
$$

with certain continuity conditions on $f(x), f^{\prime}(x), \cdots, f^{(n)}(x)$ and a simple restriction on the system of pairs $\left(\kappa_{\iota}, x_{\iota}\right)$, Mr. Birkhoff derives a general remainder theorem

$$
\begin{aligned}
f^{\left(\kappa_{0}\right)}\left(x_{0}\right)= & F^{\left(\kappa_{0}\right)}\left(x_{0}\right) \\
& +\frac{f^{(n)}\left(\xi_{1}\right)-\frac{E}{1-E}\left[f^{(n)}\left(\xi_{\imath}\right)-f^{(n)}\left(\xi_{1}\right)\right]}{n !} \cdot \psi^{\left(\kappa_{0}\right)}\left(x_{0}\right)
\end{aligned}
$$

for an arbitrary derivative $\left(\kappa_{0}\right)$ at an arbitrary point $x_{0}, E$ not independent of $\left(\kappa_{0}, x_{0}\right)$. All the known remainder theorems come directly under the case $\kappa_{0}=0, E=0$. The application to a general mean value theorem and the problems of interpolation follow.

Columbia University. F. N. Cole.

\title{
REPORT ON THE REQUIREMENTS FOR THE MASTER'S DEGREE.
}

\section{PRESENTED TO THE CHICAGO SECTION OF THE AMERICAN MATHEMATICAL SOCIETY AND RECOMMENDED FOR PUBLICATION, JANUARY 1, 1904.}

At the Christmas meeting of the Chicago Section of the American Mathematical Society, held January 2 and 3, 1902, a committee was appointed to consider and report a scheme of requirements for candidates proceeding to their second degree, with mathematics as their major subject. It was thought that a mathematical programme generally adopted in the central west would facilitate the migration of students from one institution to another, thus permitting students to take portions of 
their mathematical work at different institutions; that it would tend to preserve the value of the master's degree by making it represent equivalent attainments; and that it would enable the smaller colleges better to arrange their elective studies, so that students intending to make mathematics a specialty could, by a proper selection, obtain sufficient mathematical training to enter at once after graduation upon work which might be counted toward the master's degree.

This committee through its chairman sent a circular letter of inquiry to seventeen institutions of the central West, including all of the state universities from Ohio to Colorado, and others which may be regarded as of the same rank, or in which the mathematical department is especially strong. This letter invited a free discussion both as to the actual practice in these institutions and as to what might seem desirable as a mathematical programme covering both the undergraduate work and that leading to the second degree. As a basis of undergraduate work it was assumed that the student enters college with a thorough knowledge of algebra through quadratic equations and with plane and solid geometry. It was also assumed that the master's degree is to be conferred upon the successful completion of one year of graduate work, and that the college course covers four years of academic training. The scope of the inquiry is shown by the questions asked. They were as follows :

1. What should be the minimum acceptable time devoted to undergraduate mathematics?

2. What subjects should be included in the undergraduate course in pure mathematics? How much time should be devoted to each?

3. Should applied mathematics be required ? What subjects, and how much?

4. Should French and German, one or both, be required? If only one, which one?

5. Should the candidate for the master's degree be required to pass a more rigorous examination than is required of the undergraduate?

6 . Should a thesis be required?

7. Should the graduate work leading to the master's degree be confined to one, two, or three departments?

In order to make it more easily interpreted in the particular system of accrediting subjects at the several institutions, the 
committee has formulated its report in terms of recitation hours ; thus a subject coming five times a week for one year of 36 weeks is assigned 180 hours.

After canvassing the replies from the institutions mentioned above, the committee submits the following mathematical programme as giving the minimum preparations which should be accepted as sufficient for entering upon graduate work. It further reports a programme of graduate work, which is recommended as the minimum basis for granting the second degree.

1. The minimum time devoted to mathematics in the undergraduate course should be 540 hours. This means that at least one-fourth of the student's undergraduate work should be devoted to the study of mathematics, if he expects to secure his master's degree in mathematics after one year of resident graduate study. Whether this amount, or more, be taken, it is recommended that it be distributed throughout the four years of the undergraduate course, to the end that the continuity of his mathematical study may not be disturbed as the student passes from his undergraduate to his graduate work.

2. The 540 hours mentioned above should be distributed substantially as follows:

I. College algebra, including the elements of determinants; trigonometry; and analytic geometry, including an introduction to solid analytic geometry. 180 hours.

II. Differential and integral calculus, differential equations, and mechanics. 225 hours.

III. Advanced algebra, including the general theory of equations ; modern analytic and synthetic geometry, or solid analytic geometry. 135 hours.

3. The undergraduate instruction, especially in its earlier stages, should, by well chosen illustrations and applications, be kept in close contact with the physical sciences. Logical statement and proofs of theorems should always be delayed until their meaning is made familiar by application to special cases, and the problems considered for such purposes should be such as arise naturally out of concrete experiences. Whenever possible, a physical or a graphical solution of the problem should be given. In all mathematical teaching a clear comprehension of ideas and their correlation are of prime importance. In the earlier stages of any subject these can in general be best 
secured through the physical senses and by a method analogous to that of the general science laboratories. Abstract analysis should arise naturally in the effort to devise the most precise, clear, and convenient method of formulating and expressing the results of experiments and observations; and only in the later stages should it become an object of thought and investigation.

4. Upon the basis of the preparation indicated above, it is the opinion of the committee that the work leading to the master's degree should include at least 270 hours selected from the following groups of subjects. The selection should in any case include subjects from at least two of the three groups.

\section{Geometry.}

Projective geometry.

Modern analytic geometry, algebraic curves and surfaces. Application of calculus to twisted curves and surfaces. (Differential geometry.)

Solid analy tic geometry.

Descriptive geometry (Darstellende Geometrie).

\section{Analysis.}

Theory of equations. Advanced calculus. Theory of functions. Differential equations. Theory of numbers. Invariants.

\section{Applied Mathematics.}

Analytic mechanics.

Mathematical astronomy.

Mathematical physics.

Mathematical theory of probability.

This arrangement provides that the candidate, in case he enters upon his graduate work with the minimum mathematical preparation indicated above, and hence having a broader general training in his undergraduate course, should be required to take at least two thirds of his year's graduate work in pure and applied mathematics. On the other hand, as it may be assumed that the student entering upon his graduate work with a 
larger mathematical credit than this has had less general training in his undergraduate course, it is the opinion of the committee that he should be permitted to take as much as one half of his work in departments other than mathematical, providing, however, that the minimum requirement in mathematics indicated above is also fulfilled.

5. The candidate for a second degree should enter upon his graduate work with a sufficient knowledge of German to enable him to read easily mathematical works in that language. The committee thinks it very desirable that he should have also a reading knowledge of French.

6. It is the opinion of a large majority of the institutions with which the committee has corresponded, as well as the opinion of the committee, that in all cases a thesis should be required. This may not, and in most cases cannot, be in the strictest sense original research. It is, however, a convenient way of testing the student's ability to carry on independent investigation, and gives him an excellent preparation for research work later.

7. The examination of the candidate for a master's degree should be distinguished as to rigor and perhaps as to character from the ordinary term by term examination of the undergraduate student. Two plans are proposed, either of which, or a combination of the two, is commended.

(a) That the candidate be permitted to take the term by term examinations, as in the case of undergraduates, but that he should be expected to earn a higher grade than would entitle him to pass in case he were an undergraduate.

(b) That he be required to pass a final examination at the time of taking his degree covering all of the subjects included in his graduate course.

The committee finds a great diversity of practice as to the amount of mathematics which is made the basis of graduate work at the various institutions mentioned at the beginning of this report. It believes, however, that the programme outlined above is within the reach of all. Furthermore, upon comparison with the requirements at several of the leading American universities, it was found that the minimum requirements which are here recommended are in substantial accord with the minimum requirements for the master's degree at these institutions.

It is the thought of the committee that, as meeting the above requirements in preparation for graduate work, the work of no 
institution claiming college grade should be accepted unless the major part of the work in preparation has been taken under the direction of mathematical instructors who have themselves done the equivalent of the work here outlined for the master's degree in mathematics.

By the adoption of the above mathematical programme by the institutions represented in the Chicago Section, it is believed that a substantial service would be rendered the study of mathematics in the central west, not only by securing the advantage of uniformity in granting the second degree, but by elevating in some cases the standard upon which the degree is granted, and perhaps more than all else by giving to the small college, aiming to prepare for graduate work, a standard by which it may best arrange its elective system.

C. A. WALDO, Chairman,

E. J. Townsend,

Oskar Bolza,

Committee.

\section{ON THE SUBGROUPS OF ORDER A POWER OF $p$ IN THE LINEAR HOMOGENEOUS AND FRACTIONAL GROUPS IN THE $G F\left[p^{n}\right]$.}

BY PROFESSOR L. E. DICKSON.

(Read before the American Mathematical Society, February 27, 1904.)

1. This paper relates primarily to the subgroups $G$ of order the highest power of $p$ in the $m$-ary general and special linear homogeneous groups and the linear fractional group in the $G F\left[p^{n}\right]$. For the latter groups the question of the minimum index of subgroups is of importance in various applications of group theory. A knowledge of the properties of $G$ contributes materially towards an answer to this question, as will be shown in a subsequent note.

2. Notations. - The general linear homogeneous group $G L H\left(m, p^{n}\right)$ of all $m$-ary transformations in the $G F\left[p^{n}\right]$ has the order

$$
\begin{gathered}
\Omega_{m, p^{n}}=\left(p^{n m}-1\right)\left(p^{n(m-1)}-1\right) \cdots\left(p^{n}-1\right) p^{\mu n}, \\
{\left[\mu \equiv \frac{1}{2} m(m-1)\right] .}
\end{gathered}
$$

